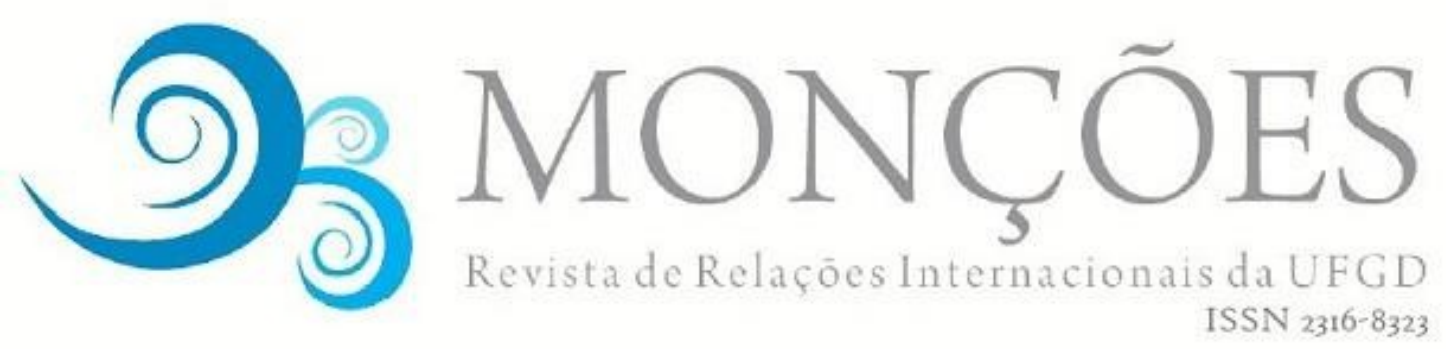

\title{
A ATUAÇÃO DAS NAÇÕES UNIDAS NO PROCESSO DE SIGNIFICAÇÃO DO MEIO AMBIENTE SAUDÁVEL COMO UM DIREITO HUMANO
}

\begin{abstract}
IARA ROCHA GUIMARÃES
Mestranda em Relações Internacionais pela Universidade Federal de Uberlândia. Pesquisadora do Núcleo de Pesquisa e Estudos em Direitos Humanos (IERI-UFU).

THAÍS MARIA DELARISSE

Mestranda em Relações Internacionais pela Universidade Federal de Uberlândia. Pesquisadora do Núcleo de Pesquisa e Estudos em Direitos Humanos (IERI-UFU).
\end{abstract}

CRISTINA YUMIE AOKI INOUE

Doutora em Desenvolvimento Sustentável pela Universidade de Brasília. Professora do Instituto de Relações Internacionais da Universidade de Brasília.

RESUMO: A significação do meio ambiente saudável como um direito humano foi construída ao longo da segunda metade do século XX e contou, ao longo desse processo, com a participação ativa da Organização das Nações Unidas. Este artigo traça a evolução do entendimento da interdependência entre os direitos humanos e o meio ambiente, ressaltando a atuação das Nações Unidas tanto como lócus de debate, que ecoou demandas de vários stakeholders, quanto a colocando como mais um ator a influenciar o processo político de definição e solução de desafios contemporâneos. Para tanto, pretende-se, a partir de uma revisão da literatura, demonstrar a construção e posterior sobreposição das agendas de meio ambiente e direitos humanos e analisar as estratégias criadas pela instituição para promover essa agenda conjunta que, sobretudo, desde 1992 foi implementada em torno do conceito de desenvolvimento sustentável.

PALAVRAS-CHAVE: direitos humanos; meio ambiente; Organização das Nações Unidas.

\section{THE UNITED NATIONS PERFORMANCE IN THE PROCESS OF MEANING THE HEALTHY ENVIRONMENT AS A HUMAN RIGHT}

\begin{abstract}
The meaning of the healthy environment as a human right was built in during the second half of the twentieth century and has, throughout this process, involved the active participation of the United Nations. This article traces the evolution of the understanding of the interdependence between human rights and the environment, emphasizing the United Nations as a locus of debate that echoed the demands of several stakeholders, as well as placing it as one more actor to influence the political process of definition and solution of contemporary challenges. In order to do so, it is intended, based on a review of the literature, to demonstrate the construction and subsequent overlapping of
\end{abstract}


environmental and human rights agendas and to analyze the strategies created by the institution to promote this joint agenda, which, since 1992, has been implemented around the concept of sustainable development.

KEYWORDS human rights; environment; United Nations.

\section{Introdução}

A Organização das Nações Unidas (ONU) emerge ao final da Segunda Guerra Mundial demarcando a construção de uma nova era na política internacional. Com o intuito de promover a paz e a estabilidade globalmente, bem como de evitar a repetição de grandes tragédias que pudessem afetar a humanidade, a ONU foi incumbida de conceber novos padrões de comportamento, muitos dos quais compuseram e deram origem à Declaração Universal dos Direitos Humanos (DUDH), um dos documentos mais simbólico desse novo período, em vista de sua pretensão em criar diretrizes capazes de guiar as ações dos Estados, a fim de garantir o respeito à vida humana.

Observamos que a ONU atuou como lócus de discussão, promovendo espaços para que múltiplos atores pudessem interagir e tratar os desafios que afetam a humanidade. Contudo, conforme as organizações internacionais conquistaram maior espaço no sistema, em paralelo à organização de espaços de debate, a ONU adquiriu poder de agência, apresentando-se como ator-chave para lidar com os problemas contemporâneos, criando novas estratégias de atuação que se aproximam da sociedade civil, fomentando a ação local para conquistar objetivos globais.

Sendo assim, para a consecução deste artigo partimos da perspectiva construtivista, demonstrando não só que as organizações internacionais importam, mas principalmente, que desempenham um papel fundamental na construção e difusão de significados, bem como atuam na concepção de medidas capazes de superar os desafios que afetam o mundo. De modo específico, o artigo analisa o papel desempenhado pela Organização das Nações Unidas no processo de significação do meio ambiente saudável como um direito humano.

Para fortalecer nosso argumento, fizemos uma revisão das principais conferências e normativas internacionais de direitos humanos e meio ambiente. Além disso, analisamos os documentos oficiais das Nações Unidas, como 
normativas e relatórios apresentados durante as reuniões promovidas pela organização. Como não temos a pretensão de realizar uma revisão exaustiva da literatura, selecionamos artigos e livros de importantes autores que versam sobre ambas as agendas e teóricos das Relações Internacionais para embasar nossa análise.

Este artigo está organizado em duas seções, além desta introdução e das considerações finais. A primeira parte inicia-se com uma descrição das organizações intergovernamentais nas teorias de Relações Internacionais, com ênfase na ótica construtivista, para então apresentar um panorama da construção das agendas de direitos humanos e de meio ambiente. Já a segunda seção possui um caráter mais analítico, apresentando como a ONU agiu ao longo destes setenta anos - desde a promulgação da Declaração Universal dos Direitos Humanos - para promover a agenda de direitos humanos, adaptando-a para as necessidades atuais, como 0 desenvolvimento sustentável. Nesse sentido, apresentamos como a organização tem promovido a interseção das agendas de direitos humanos e meio ambiente até seus esforços mais recentes, com a criação dos Objetivos do Desenvolvimento Sustentável (ODS).

\section{A construção do meio ambiente saudável como direito humano na agenda internacional}

O papel desempenhado por atores não estatais na política internacional tem se tornado mais relevante conforme aumenta a notoriedade, nas discussões globais, de temas que transcendem as fronteiras nacionais. A década de 1970 é vista como um marco neste processo, na medida em que as correntes teóricas que visavam conectar as esferas transnacional e nacional se estruturam, agregando ao debate sobre a política internacional ao sublinhar o impacto da atuação desses novos atores nas decisões dos Estados (ROCHESTER, 1986; MARTIN; SIMMONS, 1998).

Em contraposição às teorias mainstream que dominaram os debates internacionais até meados do século $X X$, as abordagens que emergem no final do século apresentam uma interpretação mais subjetiva do cenário internacional. 
Dentre elas está o construtivismo, cuja percepção parte da premissa de que os interesses são exógenos aos atores e, portanto, socialmente construídos.

Sendo assim, os teóricos desta corrente concentram seus esforços na compreensão do papel que as normas, as ideias, os valores e a cultura desempenham na política internacional. No processo de disseminação de normas, esta abordagem reconhece o poder de agência das organizações internacionais e, por conseguinte, sua capacidade de ensinar aos Estados novas formas de comportamento (FINNERMORE; SIKKINK, 2001). Sob esta ótica, estas instituições são vistas como atores capazes de moldar entendimentos e atuar no mundo social, onde são consideradas sujeitos legítimos e com reconhecido poder de fala, em decorrência da expertise e "neutralidade" que possuem em seus ambientes (HERNANDEZ, 2015).

As instituições, na condição de fóruns, também são utilizadas por outros sujeitos para expor suas demandas. Esses espaços são aproveitados para a discussão de ideias, que de acordo com Béland e Cox (2010) moldam interpretações sobre problemas políticos, através das quais são delimitados objetivos e estratégias com o propósito de alcançar determinados resultados políticos.

A criação de declarações, resoluções, conferências e convenções auxiliam as instituições no processo de estabelecimento de uma agenda a ser seguida, circunscrevendo os problemas a serem tratados e as ações que devem ser adotadas para resolvê-los. Nesse quesito, o fortalecimento da ONU foi visto como um ponto de inflexão nos estudos a respeito das organizações internacionais, na medida em que ao se apresentar como novo âmbito de discussões, de alcance global e função geral, forneceu material para revigorar as pesquisas da área, que passaram a enfatizar a instituição em seus trabalhos.

A agenda da ONU, em especial após o fim da Guerra Fria, torna-se mais permeável a atuação de outros sujeitos que, ao observarem a reorientação do foco da instituição de questões de segurança para temas relacionados ao bem-estar dos indivíduos, aproveitaram a oportunidade para influenciar as pautas de discussão ao expor as demandas sociais que afligem os indivíduos nos âmbitos domésticos (JUTTA, 2007).

Ainda de acordo com Jutta (2007), durante a década de 1990 várias conferências especializadas foram realizadas pela $\mathrm{ONU}$, as quais contribuíram para 
moldar a agenda da organização. Destacam-se, nesse contexto, a Conferência das Nações Unidas sobre o Clima, Meio Ambiente e Desenvolvimento, de 1992, a Conferência Mundial de Direitos Humanos, de 1993, e a Cúpula Mundial para o Desenvolvimento Social ocorrida em 1995. Consoante a autora:

Estas conferências proveram oportunidades às ONGs para introduzir e circular ideias. Primeiro, elas foram organizadas com o intuito de identificar novos itens para as agendas ou de desenvolver planos de ação para as agendas já existentes. Segundo, estas conferências contaram com a presença de maioria dos membros da ONU e receberam uma cobertura midiática considerável ${ }^{1}$ [...] (JUTTA, 2007, p. 24, tradução nossa).

Reconhece-se neste artigo a importância desempenhada pela Organização das Nações Unidas, tanto como ator autônomo que molda significados e dissemina normas, como um fórum legítimo a partir do qual outros atores aproveitam para apresentar e discutir suas demandas no processo político de significação do meio ambiente saudável como um direito humano. Portanto, o intuito desta e da próxima seção é o de apresentar e analisar o desenvolvimento desse entendimento desde as primeiras normativas sobre os temas até os esforços mais recentes.

\subsection{A construção da agenda de direitos humanos}

Há um debate constante na comunidade científica acerca da origem e significação dos direitos humanos. Cmiel (2004), ao reconstruir os passos trilhados pelo ideário que sustenta o que hoje entendemos por direitos humanos, cita vários momentos importantes da história moderna e deles estabelece como marco a Declaração dos Direitos do Homem e do Cidadão, elaborada no seio da Revolução Francesa ${ }^{2}$.

Outro ponto alvo de divergência alude à forma como os direitos humanos são estruturados. De um lado, os teóricos que defendem a doutrina de gerações (BONAVIDES, 1993) argumentam que os direitos humanos podem ser separados

\footnotetext{
1 "These conferences provided opportunities for NGOs to introduce and circulate their ideas. First, they had been organized with the intention to identify new agenda items or to develop action plans for existing ones. Second, these conferences were attended by the majority of UN member states and received quite a bit of media coverage."

${ }^{2}$ A Declaração originou de discussões a respeito dos direitos naturais, a qual apresentou a ideia de que os cidadãos tinham direitos que deveriam ser respeitados, mesmo que à época o conceito de cidadão excluísse grande parcela da sociedade.
} 
em diferentes dimensões conforme novos grupos de direitos surgem ${ }^{3}$. De outro, os críticos a essa abordagem (ROMITA, 2007; PIOVESAN, 2010; WEIS, 2010; MAZZUOLI, 2013; CANÇADO TRIDANDE, 2003) defendem que tal entendimento deixa subentendido que existem alguns direitos que são mais importantes que outros, quando na verdade todos os direitos humanos são indivisíveis e interdependentes.

Independente da origem dos significados atribuídos aos direitos humanos e da forma como estão estruturados, o que se percebe é que este não é um assunto contemporâneo e suas raízes encontram-se na arena doméstica, diante do reconhecimento, pelos grupos sociais, de novas necessidades. Corrobora com esta ótica a definição de direitos humanos apresentada por Perez Luño (2005), os quais são entendidos como

[...] um conjunto de faculdades e instituições que, em cada momento histórico, materializam as exigências da dignidade, liberdade e igualdade humana, as quais devem ser reconhecidas e positivadas pelos ordenamentos jurídicos a nível nacional e internacional ${ }^{4}$ (LUÑO, 2005, p. 50, tradução nossa).

Partindo da concepção de Luño (2005), pode-se dizer que as práticas desumanas perpetradas durante a Segunda Guerra Mundial (1939-1945) concretizaram a necessidade de se criar uma estrutura de entendimentos e normativas que coibissem a repetição das atrocidades cometidas naquele período. Para Flávia Piovesan (2004)

É nesse cenário que se desenha o esforço de reconstrução dos direitos humanos como paradigma e referencial ético a orientar a ordem internacional contemporânea. Se a Segunda Guerra significou uma ruptura com os direitos humanos, o pós-guerra deveria significar sua reconstrução

\footnotetext{
${ }^{3}$ De acordo com essa abordagem, até o ano de 2008 foram estabelecidas 6 gerações de direitos. A primeira remonta à Revolução Francesa, sendo caracterizada pelo direito à liberdade; a segunda geração alinhada ao direito à igualdade teria surgido no âmbito do Estado de bem-estar social; a terceira, a seu turno, está associada à fraternidade e se origina a partir das disputas sociais que caracterizaram os séculos XIX e XX. Por sua vez, a quarta geração relaciona-se ao biodireito, haja vista os experimentos genéticos realizados durante a Segunda Guerra Mundial; a quinta geração alude ao direito à paz; e, por fim, a sexta geração está associada ao direito à democracia, à informação e ao pluralismo (FURTADO; MENDES, 2008).

4 "[...] un conjunto de facultades e instituciones que, en cada momento histórico, concretan las exigencias de la dignidad, la libertad y la igualdad humanas, las cuales deben ser reconocidas positivamente por los ordenamientos jurídicos a nivel nacional e internacional."
} 
(PIOVESAN, 2004, p. 22).

A criação da Organização das Nações Unidas, em 1945, marca o início desse esforço da humanidade de reconstruir os direitos humanos. Prova disso é a promulgação da Declaração Universal dos Direitos Humanos, em 1948, a partir da qual se estrutura e consolida a gramática contemporânea dos direitos humanos ${ }^{5}$ no plano internacional.

Ao dispor que "são aqueles inerentes a todos os seres humanos, independente de raça, sexo, nacionalidade, etnia, idioma, religião ou qualquer outra condição" (ONU, 1948, art. $2^{\circ}$ ), a DUDH apresenta-se como o primeiro documento global que define o campo semântico dos direitos humanos. Além disso, o conjunto de artigos da DUDH deixa expresso a natureza universal, indivisível, inalienável, inter-relacionada e interdependente destes direitos.

A partir do documento de 1948 emerge um sistema internacional de promoção e proteção dos direitos humanos, bem como o Direito Internacional dos Direitos Humanos, que alicerça a criação de importantes tratativas no plano internacional para assegurá-los. Dentre elas destacam-se o Pacto Internacional dos Direitos Civis e Políticos e o Pacto Internacional dos Direitos Econômicos, Sociais e Culturais ambos de 1966, que em conjunto com a DUDH compõem a Carta Internacional dos Direitos Humanos.

Em paralelo ao trabalho desempenhado pelo sistema global de proteção, liderado pela atuação da ONU, outros importantes documentos foram estabelecidos nos continentes Europeu, Americano e Africano ${ }^{6}$ para contribuir com a construção da agenda dos direitos humanos. Esses três sistemas atuam em conjunto com o regime

\footnotetext{
${ }^{5}$ Os estudiosos dos direitos humanos não possuem um consenso a respeito do marco específico a partir do qual inicia-se a construção da noção contemporânea dos direitos humanos. Nesse sentido, Moyn (2014) é um dos autores que contestam como ponto de partida o pós-Segunda Guerra Mundial como momento em que os direitos humanos começam a ser concebidos. Segundo o autor, a percepção desses direitos é algo que remete aos anos 1970, uma vez que é nesse momento em que a descolonização se concretiza, além de ser o instante em que os cidadãos ocidentais entram em contatos com os direitos humanos após suas fracassadas tentativas de adesão de outros modelos políticos, tal qual o socialismo.

${ }^{6}$ A saber: a Convenção Europeia dos Direitos Humanos criada em 1950, a qual deu embasamento para a criação do Sistema Europeu de Direitos Humanos; a Declaração dos Direitos e Deveres do Homem de 1948 e a Convenção Americana dos Direitos Humanos (1969), os quais deram substrato ao Sistema Interamericano de Direitos Humanos; e a Carta Africana sobre os Direitos Humanos e dos Povos de 1981 e o Protocolo à Carta Africana sobre os Direitos Humanos e dos Povos (1998), os quais fundamentam o Sistema Africano (HEYNS; PADILLA; ZWAAK, 2006).
} 
global, contribuindo para a efetivação dos princípios estabelecidos pela DUDH, ao mesmo tempo em que abarcam as particularidades de suas regiões, buscando medidas para mitigar os desafios persistentes em seus contextos (HEYNS; PADILLA; ZWAAK, 2006).

Os regimes regionais de proteção estão ancorados em normativas e estruturas que salvaguardam os direitos humanos ao estabelecerem mecanismos que constrangem os Estados a cumprirem com o seu dever de promover e proteger os direitos inerentes aos seus cidadãos (BUERGENTHAL, 2006). Não obstante, ao longo da história, avanços e retrocessos marcaram a pauta de direitos humanos, tanto na arena global, como a nível regional.

Já na década de 1990, o fim da polaridade Leste/Oeste somou à outras variáveis que contribuíram para o desenvolvimento da agenda dos direitos humanos. Nesse contexto, a ONU organizou, em 1993, a Conferência Mundial de Direitos Humanos, que apesar dos intensos debates e divergências que marcaram o evento em Viena, apresentou como importantes resultados a recomendação de criação do Alto Comissariado das Nações Unidas para os Direitos Humanos (ACNUDH) e a Declaração de Direitos Humanos de Viena.

Na reunião da Assembleia Geral das Nações Unidas daquele ano estava em pauta as recomendações estipuladas na Conferência e, atendendo ao consenso formado em Viena, foi autorizada a criação do ACNUDH (BOYLE, 1995). Sendo reconhecido globalmente como o principal órgão da ONU para tratar das questões relativas à promoção e proteção dos direitos humanos, a institucionalização do Alto Comissariado representa o avanço dos direitos humanos na agenda internacional (HERNANDEZ, 2015).

Já a respeito da Declaração de Viena, é importante destacar que o documento de 1993 não só reitera a validade dos princípios e valores da DUDH e a necessidade dos Estados de garantirem a proteção desses direitos universalmente, como também incorporou novas preocupações, fundindo-se a outras agendas como a de meio ambiente. Além disso, representou um passo relevante no Direito Internacional dos Direitos Humanos na medida em que ampliou a representatividade das normativas sobre o tema no plano global, ao ter sido endossada por 171 Estados em contraposição aos 48 que consentiram com a DUDH (PIOVESAN, 2006). 
Neste sentido, o que se observa é que ao longo destes setenta anos de história, a comunidade internacional deparou-se com desafios globais nos quais a salvaguarda dos direitos humanos torna-se imprescindível e central na agenda contemporânea, ao lado de questões vinculadas ao meio ambiente e ao desenvolvimento. Nesse contexto, os princípios presentes na DUDH transformam-se em guias que reverberam em outras agendas e normativas internacionais.

Com um conteúdo que define parâmetros elementares para a proteção do ser humano, a DUDH tornou-se ponto de partida para que outros documentos de amplitude global surgissem como apoio aos direitos fundamentais, inclusive em outras searas. A propagação do texto da Declaração em discursos de ativistas, políticos e grupos sociais consolidou a linguagem dos direitos humanos e disseminou seus princípios, fazendo com que a população mundial reconhecesse esses direitos também em outras áreas.

\subsection{A construção da agenda de meio ambiente}

Com o início das transformações socioeconômicas promovidas pela Revolução Industrial, a partir do século XVIII, emergiram novos padrões de produção e consumo baseados na intensa exploração da natureza. Visto como um meio para alavancar a economia das nações, o uso desmedido dos recursos naturais foi amplamente defendido como uma necessidade a ser perseguida tanto pelos países desenvolvidos, como por aqueles em desenvolvimento (LEITE; AYALA, 2004).

Não obstante, a modernização apresentou como efeito colateral a intensificação dos desastres ecológicos, uma forma da natureza de demonstrar sua incapacidade de manter-se equilibrada frente ao novo estilo de vida proposto pelos países ocidentais. Diante deste contexto, a partir da segunda metade do século XX, a comunidade científica reúne os primeiros esforços para colocar o meio ambiente na agenda dos tomadores de decisão.

$\mathrm{Na}$ década de 1960, ambientalistas começaram a expor a degradação ambiental como ameaça à vida humana, reiterando a importância do uso saudável do meio ambiente como garantia para a manutenção do bem-estar da humanidade (CARSON, 1962). A consciência sobre os danos ao meio ambiente gerados pela 
ação antrópica e seus sistemas de produção e consumo despertou as organizações não governamentais e científicas, que chamaram à ação Estados, organizações internacionais e, em certa medida, as empresas para priorizar as agendas ambiental e de direitos humanos nos debates.

Como reflexo desse processo houve, em 1968, a criação do Clube de Roma - uma iniciativa que reuniu empresários, economistas e cientistas para discutir os problemas globais a partir da análise dos padrões de crescimento econômico (BRÜSEKE, 1998). Da mesma forma, ocorre também naquele ano, durante a $23^{\circ}$ sessão da Assembleia Geral das Nações Unidas, a primeira manifestação significativa sobre a necessidade de um meio ambiente saudável para 0 aproveitamento integral dos direitos humanos.

Segundo Perrez (2004), o documento resultante foi o primeiro da ONU a identificar a ligação entre essas duas temáticas. Na resolução, que tinha a intenção de considerar os problemas existentes entre o relacionamento do homem com a natureza, é ressaltada a preocupação com o bem-estar da humanidade e o gozo dos direitos humanos ${ }^{7}$ (UNGA, 1968).

A consciência de que 0 desgaste ambiental transpunha as fronteiras nacionais dos Estados firmou a percepção de que a solução deveria ser arquitetada a partir da ação coordenada de múltiplos atores em diferentes níveis de atuação (CHASEK; DONWIE; BROWN, 2017). Sobre isso, o documento de 1968 acatou a indicação das Nações Unidas de realizar uma conferência internacional para tratar do assunto.

Quatro anos mais tarde, o Clube de Roma expôs suas preocupações com a preservação do meio ambiente através da publicação do relatório "Os Limites do Crescimento" (BRÜSEKE, 1998). Dentre outras questões, o estudo apresentava como problemas a serem enfrentados pela humanidade 0 avanço da industrialização, o crescimento populacional, a escassez de alimentos e o esgotamento dos recursos naturais.

A obra repercutiu mundialmente, despertando novas pesquisas no ambiente acadêmico sobre a relação entre desenvolvimento econômico e meio ambiente diante das necessidades e interesses dos novos tempos. Talvez pelo tom

\footnotetext{
${ }^{7}$ A Resolução 2398 (XXIII) foi adotada pela Assembleia Geral em dezembro de 1968 sob o título "Problems of the human environment".
} 
"apocalíptico" do relatório, o estudo se popularizou e foi capaz de sensibilizar as pessoas para os desafios que a humanidade enfrentaria caso permanecessem ignorando os sinais da natureza (BRAUN, 2005). O intuito do Clube de Roma era questionar a viabilidade de continuar com os padrões de crescimento econômico vigentes na época e repensar novas atitudes que garantissem a saúde do meio ambiente.

Ainda em 1972, a ONU realizou na cidade de Estocolmo, a Conferência sobre o Meio Ambiente Humano. A reunião foi a primeira da organização em que 0 debate acerca do meio ambiente era a pauta central. Mais do que isso, o evento em Estocolmo simboliza o início da construção da agenda internacional de meio ambiente e do Direito Internacional do Meio Ambiente, com a promulgação da Declaração da Conferência das Nações Unidas sobre o Meio Ambiente Humano.

O documento, ao estipular um conjunto de normas e de boas práticas para enfrentar os impactos ambientais, derivados dos avanços tecnológicos para o desenvolvimento, chancela a preocupação internacional de que é necessária a proteção do meio ambiente para que a humanidade possa usufruir uma vida saudável. Assim, a Declaração constata que

\begin{abstract}
O homem é tanto criatura quanto moldador do seu ambiente, o que the concede sustento físico e the oferece a oportunidade de crescimento intelectual, moral, social e espiritual. Na longa e tortuosa evolução da raça humana neste planeta um estágio foi atingido quando, através da rápida velocidade da ciência e tecnologia, o homem alcançou o poder de transformar seu ambiente em inúmeras formas e em uma escala sem precedente. Ambos os aspectos do ambiente do homem, o natural e o construído, são essenciais para o seu bem-estar e para o aproveitamento dos direitos humanos básicos - até mesmo o direito à própria vida ${ }^{8}$ (UN, 1972, p. 03, tradução nossa).
\end{abstract}

As discussões realizadas em Estocolmo foram embasadas nas ideias disseminadas pelo relatório "Limites do Crescimento" (BRAUN, 2005). Os pareceres categóricos a respeito do crescimento econômico estipulados pelo documento do Clube de Roma fomentaram divergências ao longo do encontro entre os Estados

\footnotetext{
8 "Man is both creature and moulder of his environment, which gives him physical sustenance and affords him the opportunity for intellectual, moral, social and spiritual growth. In the long and tortuos evolution of the human race on this planet a stage has been reached when, through the rapid acceleration of Science and technology, man has acquired the power to transform his environment in countless ways and on an unprecedented scale. Both aspects of man's environment, the natural and the man-made, are essential to his well-being and to the enjoyment of basic human rights - even the rights to life itself."
} 
presentes. Com suas economias em processo de desenvolvimento, os países do Sul global estavam direcionados para avançá-las e, por isso, assumiram posturas reticentes em relação às propostas que limitassem o crescimento econômico.

Apesar dos importantes avanços conquistados na ocasião, a Conferência de 1972 foi incapaz de promover o consenso entre os países desenvolvidos e os em desenvolvimento em relação às expectativas de crescimento. Contudo, tal discussão não foi abandonada, ao contrário, os impactos do crescimento econômico para o meio ambiente tornaram-se objeto de estudo da Comissão Mundial sobre o Meio Ambiente e o Desenvolvimento Humano, criada pela Assembleia Geral da ONU, em 1983.

Compostas por estudiosos da área e liderada pela ex-primeira ministra norueguesa, Gro Harlem Brundtland, a Comissão ficou conhecida pela publicação, em 1987, do relatório "Nosso Futuro Comum" ou Brundtland. O intuito do texto era apresentar medidas para balizar os interesses econômicos e o equilíbrio ambiental, oferecendo como ponto de partida o desenvolvimento sustentável, definido naquele momento como

[...] um processo de mudança no qual a exploração dos recursos, o direcionamento dos investimentos, a orientação do desenvolvimento tecnológico e a mudança institucional estão em harmonia e reforçam o atual e futuro potencial para satisfazer as aspirações e necessidades humanas ${ }^{9}$ (UN, 1987, tradução nossa).

O relatório Brundtland institucionaliza um conceito de desenvolvimento sustentável que, em razão de sua amplitude, incentivou a criação de múltiplas significações e derivações no âmbito acadêmico/científico (REDCLIFT, 1987; PEARCE ET AL, 1989; RICHARDSON, 1997; WACKERMANN, 2008). Todavia, independente dos termos e acepções criados, é possível argumentar que o estudo instituiu as bases para que a comunidade internacional repensasse a ideia de desenvolvimento, permitindo à todas as nações buscar o desenvolvimento econômico, mas por meio de estratégias que preservassem o meio ambiente.

Diferente do "Limites do Crescimento", que coloca em polos opostos as economias desenvolvidas e aquelas em desenvolvimento, o "Nosso Futuro Comum"

\footnotetext{
9 "[...] a process of change in which the exploitation of resources, the direction of investments, the orientation of technological development; and institutional change are all in harmony and enhance both current and future potential to meet human needs and aspirations."
} 
fomenta o consenso entre as nações através da ideia de desenvolvimento sustentável. A abertura para o diálogo foi percebida em 1992, durante a Conferência das Nações Unidas sobre Meio Ambiente e Desenvolvimento - a ECO-92, Cúpula da Terra ou Rio-92 - em que os presentes levaram para o centro do debate o interesse em promover de forma conjunta soluções para garantir o desenvolvimento econômico e a proteção do meio ambiente.

A Conferência do Rio de Janeiro foi o ponto de partida para a comunidade internacional conceber a sustentabilidade e o direito ao desenvolvimento socioeconômico como indissociáveis, algo que ficou explícito no quarto princípio da Declaração do Rio (1992). Seguindo o caminho trilhado pelos manuscritos anteriores, o documento concede ao ser humano o espaço central nas preocupações sobre o desenvolvimento sustentável e reproduz traços do Direito Internacional dos Direitos Humanos ao determinar, no princípio 10, a imprescindibilidade de se assegurar os direitos à informação, à participação e às soluções e reparações jurídicas e administrativas (BOYLE, 2007).

Além deste documento, a reunião promoveu outros importantes avanços para a agenda de meio ambiente ao proporcionar a elaboração da Agenda 21 e da Convenção-Quadro das Nações Unidas sobre Mudanças Climáticas ${ }^{10}$, sendo a última o início dos diálogos para a criação do Protocolo de Kyoto, em 1997. O evento promovido no Rio de Janeiro em 1992 deixou como legado para as discussões seguintes o foco no conceito de desenvolvimento sustentável que, por sua vez ressignificou o direito ao meio ambiente saudável ao incluí-lo em sua definição.

Em consonância com esses novos propósitos, a resolução 'O Futuro que Queremos' construída, em 2012, na Conferência das Nações Unidas para o Desenvolvimento Sustentável - adiante também referenciada como Rio+20 determinou a responsabilidade de todos os Estados em atingir as metas concebidas. Seus princípios tinham como intenção assegurar simultaneamente o bem-estar da

10 A Convenção-Quadro das Nações Unidas sobre Mudanças Climáticas alude à um tratado internacional criado durante a Rio-92 para tratar especificamente dos efeitos dos gases de efeito estufa no meio ambiente e as medidas para reduzir as concentrações para impedir alterações climáticas. O tratado começou a vigorar em 1994 e utiliza as Conferências das Partes (COP) como meio de aferir se os objetivos estão sendo cumpridos (MMA, 2018). 
humanidade e do Planeta, delineando como prioridades a redução da pobreza, a promoção de equidade social e a proteção do meio ambiente (HORN, 2013).

$\mathrm{Na}$ Rio+20 a noção de desenvolvimento sustentável foi enfatizada, ao estabelecer grande parte da linguagem e das metas, que sustentam as práticas para a preservação do meio ambiente e a proteção dos direitos humanos. Essas diretrizes compõem a Agenda 2030 e, em especial, os Objetivos do Desenvolvimento Sustentável, também criados em 2012.

Apesar de haver muitos outros pontos que somam à construção das agendas de direitos humanos e de meio ambiente, nesta primeira seção buscamos apontar os principais momentos de cada agenda como substrato para, na sequência, discutir o papel desempenhado pela ONU em significar o meio ambiente saudável como um direito humano.

Parte significativa dos documentos emergidos de 1948 adiante, tanto na área dos direitos humanos quanto na ambiental não possuem caráter vinculante nem dispõem de mecanismos de implementação e de responsabilização. A despeito disso, demonstramos que sua pertinência está no fato de serem declarações que pautam discussões, além de determinarem e moldarem significados que norteiam as estratégias de atuação das organizações intergovernamentais e outros atores no cenário internacional, como veremos a seguir.

\section{O papel das Nações Unidas no processo de significação do meio ambiente como um direito humano}

As Nações Unidas exerceram um papel ativo no processo de pautar a agenda conjunta dos direitos humanos e meio ambiente, bem como em significar o meio ambiente saudável como um direito humano. Foi visto que o marco da interconectividade das duas agendas no cenário internacional está na Declaração de Estocolmo, a partir da relação entre o direito do ser humano ao bem-estar e ao ambiente digno. Neste sentido, esta seção tem como intuito demonstrar as estratégias adotadas pela organização a fim de promover este tópico na comunidade internacional. 
Os primeiros passos em direção à consolidação dessa agenda foram propiciados pela abertura, já no final dos anos 1960, de espaços de debates que apresentaram as ameaças existentes ao meio ambiente e discutiram possíveis ações para coibir os efeitos negativos da mudança climática e do uso inadequado dos recursos ambientais sobre o Planeta Terra e a vida humana. Como consequência, o bem-estar da humanidade e sua sobrevivência foram convertidos em temas prioritários da agenda, em especial durante a década de 1990, quando as demandas até então ofuscadas pelos assuntos de "alta política" ganharam mais espaço para serem ecoadas através dos organismos intergovernamentais.

Os fóruns internacionais e as conferências de cúpula convocados pelas Nações Unidas, com o intuito de avançar essa agenda, utilizaram-se da ideia de desenvolvimento (sustentável) e a direcionou aos países mais pobres do globo. A promoção desse termo estava ancorada à concepção de que a promoção do bemestar econômico está atrelada à tutela dos direitos consagrados nas declarações internacionais sobre meio ambiente e direitos humanos.

Os entendimentos a respeito do termo "sustentabilidade" e a necessidade de se associar crescimento econômico com a preservação do meio ambiente foram temas constantemente abordados em vários momentos na história mundial (PISANI, 2006). Não obstante, a acepção contemporânea do conceito "desenvolvimento sustentável" remonta à segunda metade do século XX.

Durante a década de 1970 a comunidade acadêmica e demais atores pautaram debates sobre a existência de limites naturais para o crescimento econômico. Todavia, foi com a publicação nomeada "Estratégia Mundial para a Conservação", de $1980^{11}$, que a noção de desenvolvimento sustentável foi de fato introduzida no cenário internacional, cuja definição se ancorava na ideia de conquista do desenvolvimento através da conservação dos recursos naturais. Ademais, o documento também apresentava uma preocupação com as futuras gerações e sublinhava que a conservação dos recursos naturais seria impossível caso não houvesse a proteção dos direitos fundamentais, como a garantia à todas as populações de condições mínimas de sobrevivência (HARDING, 2006).

\footnotetext{
${ }^{11}$ O documento foi elaborado em conjunto pela União Internacional para a Conservação da Natureza e dos Recursos Naturais (IUCN, sigla em inglês), pelo Programa das Nações Unidas para o Meio Ambiente (PNUMA) e pelo World Wide Fund for Nature (WWF).
} 
Apesar dessa discussão ter sido pautada quando da publicação do documento, o termo "desenvolvimento sustentável" somente foi promovido na agenda internacional a partir da Conferência das Nações Unidas sobre o Meio Ambiente e o Desenvolvimento, ocorrida em 1992, instante em que o Relatório Brundtland recebe maior evidência e oferece de acordo com Harding "[...] um slogan por trás do qual os políticos do primeiro mundo, com eleitorados verdes para apaziguar, e os políticos do terceiro mundo, com privação econômica para enfrentar, poderiam se unir"12 (HARDING, 2006, p. 232, tradução nossa).

$O$ grande foco concedido às discussões em torno do conceito de desenvolvimento sustentável nos fóruns da ONU foi o resultado de uma estratégia que tinha como intenção conceber uma solução viável ao problema do crescimento econômico. A pretensão ao disseminar este conceito globalmente era demonstrar aos Estados que seu direito ao desenvolvimento seria assegurado e que o crescimento econômico poderia ser substituído por um outro plano de crescimento que levasse em consideração não só os aspectos econômicos, mas também os sociais e os ambientais.

No documento resultante da ECO-92, além de demarcar a inclusão do "desenvolvimento sustentável" na agenda global, colocou no centro das atenções as necessidades e interesses dos seres humanos, outro resultado da promoção dessa agenda. Assim, enfatizou a imprescindibilidade da garantia do crescimento econômico de países mais pobres, ao mesmo tempo em que sublinhou a essencialidade de se assegurar condições básicas de sobrevivência à todas as populações, bem como às gerações futuras (PISANI, 2006; BOYLE, 2007).

Contudo, é importante ressaltar que a noção de desenvolvimento sustentável não foi aceita sem críticas pela comunidade internacional ${ }^{13}$. Apesar das

\footnotetext{
12 "[...] a slogan behind which first world politicians with green electorates to appease, and third world politicians with economic deprivation to tackle, could unite."

${ }_{13}$ Diversos atores direcionaram críticas à abordagem amparada pela definição de desenvolvimento sustentável. Entre eles, os Estados em desenvolvimento argumentaram que a criação dessa nova abordagem tinha como intuito Ihes impor uma nova forma de desenvolvimento que criasse limitações para seu crescimento econômico. Além disso, alguns ambientalistas alegaram que a noção de desenvolvimento sustentável não questionava a ideia de crescimento econômico além de não contestar a cultura do consumo, de modo que na prática a nova ideologia não agregava muito para a proteção do meio ambiente. Outros críticos ressaltaram a ausência de critérios específicos para auferir o progresso em relação ao desenvolvimento sustentável, sem os quais o conceito poderia ser manipulado para servir os interesses de quem tivesse a pretensão de utilizá-lo para sua própria promoção (PISANI, 2006).
} 
duras opiniões sobre a aplicabilidade do desenvolvimento sustentável e de poucos resultados práticos oriundos dessa nova abordagem, as Nações Unidas se mantiveram atuante. A partir de 1992, contudo, a ONU modifica sua estratégia e passa a atuar não só como lócus de discussão, abrindo espaço para a atuação de stakeholders, mas também se coloca como um ator no processo político. Assim, durante a ECO-92, propõe estratégias de atuação para promover o desenvolvimento econômico e garantir os direitos humanos das populações mais vulneráveis, sem deixar de lado as preocupações com o meio ambiente.

Em vista disso, também durante o evento a ONU lançou o primeiro programa de ações que ofereceu objetivos, atividades e meios de implementação para a superação dos desafios do novo século. Ao delimitar os eixos centrais que os stakeholders deveriam se concentrar ao estipular ações em busca do desenvolvimento sustentável, a estratégia lançada na ocasião inaugura uma nova abordagem da organização para atingir seus objetivos. Esse método de atuação foi replicado também na criação dos Objetivos do Desenvolvimento do Milênio (ODM) e depois nos Objetivos do Desenvolvimento Sustentável.

Desse modo, o documento apresentado na conferência no Rio de Janeiro, conhecido como Agenda 21, tinha como objetivo - diante dos desafios do novo século como o aumento da desigualdade e pobreza, o aumento da fome, o espraiamento de doenças e a cada vez mais intensa deterioração do meio ambiente - elencar variadas metas, que além de abarcar as três áreas do desenvolvimento sustentável, a social, a econômica e a ambiental, tivessem como finalidade desenvolver ações para lidar com as problemáticas observadas até então (UN, 1994).

Uma das grandes novidades do documento foi a recomendação para que os atores desenvolvessem as Agendas 21 locais, ou seja, programas que pudessem conceber métodos mais aplicáveis e urgentes aos desafios de cada região. Não obstante, o documento lançado na ECO-92 foi duramente criticado, sob o argumento de que as metas enunciadas eram muito ambiciosas e amplas para saírem do papel (NRCNA, 2002; OLIVEIRA, 2015).

Em resposta, a ONU estruturou um plano estratégico mais específico para a virada do século, os Objetivos do Desenvolvimento do Milênio. Criados a partir da 
Declaração do Milênio, em 2000 - aprovada na maior cúpula de todos os tempos ${ }^{14}$ os ODM são um conjunto de oito objetivos ${ }^{15}$ com o propósito de viabilizar, até o ano de 2015, o desenvolvimento humano, enfocando o combate à pobreza e à fome em concomitância com o estabelecimento de uma relação recíproca entre direitos humanos e desenvolvimento.

A percepção do desenvolvimento como um direito humano mantém-se como fio condutor dos ODM, na medida em que o texto da Declaração (2000) reconhece a sustentabilidade ambiental e a salvaguarda dos direitos humanos como objetivoschaves para guiarem as ações no novo milênio. Como os ODM fazem uma releitura dos artigos dispostos na DUDH, o cumprimento das metas já se enquadraria como medida protetiva dos direitos humanos em termos práticos.

Todos os objetivos do milênio foram pensados a partir dos documentos anteriores alicerçados na proteção dos direitos humanos, em especial na Declaração Universal dos Direitos Humanos. Mediante a isso, verifica-se que os oito ODM têm referência a algum direito elencado na DUDH, porém é o artigo 25 que embasa a maioria dos objetivos $(1 ; 2 ; 4 ; 5 ; 6$ e 7$)$ ao firmar que

1. Toda a pessoa tem direito a um nível de vida suficiente para the assegurar e à sua família a saúde e o bem-estar, principalmente quanto à alimentação, ao vestuário, ao alojamento, à assistência médica e ainda quanto aos serviços sociais necessários, e tem direito à segurança no desemprego, na doença, na invalidez, na viuvez, na velhice ou noutros casos de perda de meios de subsistência por circunstâncias independentes da sua vontade. 2. A maternidade e a infância têm direito a ajuda e a assistência especiais. Todas as crianças, nascidas dentro ou fora do matrimônio, gozam da mesma proteção social (ONU, 1948).

A ideia da ONU de fomentar no plano local iniciativas que contribuam com o alcance de metas globais permaneceu em sua nova empreitada. Porém, ao contrário da Agenda 21, que estruturalmente muito reflete as normativas criadas nas grandes conferências internacionais, em formatos de extensos manuais, os ODM foram apresentados em uma plataforma mais didática e acessível à sociedade civil. Essa transformação no formato contribuiu para que os ODM adquirissem maior

\footnotetext{
${ }^{14}$ Realizada no escritório da ONU nos Estados Unidos, teve a participação de representantes de 189 Estados, sendo reconhecida como a maior reunião de chefes de Estado e de governo da história (UNICEF, 2018).

15 Distribuídos em 21 metas e 60 indicadores, os oito objetivos do milênio eram: 1. Erradicar a extrema pobreza e a fome; 2 . Universalizar a educação primária; 3. Promover a igualdade entre os sexos e o empoderamento feminino; 4. Reduzir a mortalidade infantil; 5 . Melhorar a saúde das gestantes; 6. Combater o HIV/AIDS, a malária e outras doenças; 7. Garantir a sustentabilidade ambiental; 8. Estabelecer parcerias mundiais para o desenvolvimento.
} 
capacidade de disseminação e de mobilização, não ficando restritos ao público especializado.

Durante os 14 anos em que esteve em vigor, os ODM alcançaram algum progresso no que diz respeito a saúde e ao bem-estar. Entretanto, seus avanços foram limitados sobretudo em comparação com as dificuldade enfrentadas, dentre elas o não envolvimento dos países desenvolvidos; a ausência de dados confiáveis para medir o progresso das metas; e a não consideração das particularidades de cada região para a implementação dos objetivos (FEHLING; NELSON; VENKATAPURAM, 2013).

Mais do que isso, ainda que os ODM tenham referenciado em seus objetivos os direitos humanos, uma das críticas mais enfáticas direcionadas a eles versa sobre a menção tímida e a ausência de uma abordagem mais ampla no que diz respeito aos direitos humanos, ao compará-los com a Declaração do Milênio, cujo texto mostra-se mais abrangente (KNOX, 2015).

Apesar do esforço de incluir a ampla noção de desenvolvimento adotada pela ONU desde os anos 1980, os Objetivos do Desenvolvimento do Milênio não foram eficazes em refletir a interrelação existente entre as agendas de meio ambiente e a de direitos humanos. Tendo, inclusive, referenciado a questão ambiental de forma muito restrita, isolando-a de temas endereçados nas discussões anteriores. Ademais, ainda que os ODM tenham criado um novo método para se aproximar dos grupos locais, a estratégia foi voltada para os Estados em desenvolvimento, excluindo uma considerável parcela global que, por sua vez, limitou a real possibilidade de se atingir o desenvolvimento sustentável.

Ao se aproximar do limite do prazo para a implementação dos ODM, em 2012 as Nações Unidas construíram outro plano de ação e lançaram a Agenda 2030, que incorpora as preocupações do desenvolvimento sustentável e deixa claro as referências aos princípios basilares dos direitos humanos. Um dos resultados da nova agenda foi a concepção dos Objetivos do Desenvolvimento Sustentável, os quais foram construídos para suplantar as metas propostas no começo do século.

As limitações teóricas e práticas dos ODM para atingir as metas estipuladas foram internacionalmente reconhecidas. O Escritório do Alto Comissário das Nações Unidas para os Direitos Humanos as ressaltou, ao mesmo tempo em que evidenciou a potencialidade da nova agenda enfocada nos ODS, ao pronunciar que 
É altamente reconhecido que os direitos humanos são essenciais para conquistar o desenvolvimento sustentável. Os Objetivos do Desenvolvimento do Milênio serviram como um proxy para certos direitos econômicos e sociais, mas ignorou outras importantes relações entre os direitos humanos. Diferentemente, os princípios e normas dos direitos humanos são agora fortemente refletidos em um ambicioso e novo quadro de desenvolvimento global, a Agenda para o Desenvolvimento Sustentável 2030. [...] Os Objetivos do Desenvolvimento Sustentável são o resultado do processo mais consultivo e inclusivo da história das Nações Unidas. Enraizada no Direito Internacional dos Direitos Humanos, a agenda oferece oportunidades críticas para avançar ainda mais a realização dos direitos humanos para todas as pessoas, em todos os lugares, sem discriminação ${ }^{16}$ (OHCHR, 2017, s/p., tradução nossa).

O que se observa é que na teoria os ODS conseguem corrigir muitas das limitações visualizadas na criação dos ODM ao conceder mais ênfase à ideia de desenvolvimento sustentável, cuja essência se associou a uma abordagem baseada em direitos que ressalta que para se atingir a sustentabilidade é necessário o foco em três questões essenciais: o direito ao meio ambiente limpo e seguro, o acesso à informação e à participação pública nos processos de tomada de decisão e o direito de promover e defender a proteção do meio ambiente e dos direitos humanos (UNAC, 2013).

Tal qual os ODM, os ODS buscam promover os princípios elencados nos documentos internacionais que sustentam os direitos humanos. Portanto, cada um deles possui alguma conexão com as normativas sobre o tema, sendo recorrente as menções à Declaração Universal dos Direitos Humanos nos 17 objetivos $^{17}$ e nas 169 metas. Estipulada no artigo $25^{\circ}$ da DUDH, a interdependência entre bem-estar e uma vida digna embasa os ODS 2, 6, 8 e 11, que também sustentam a sobreposição entre as agendas ambiental e de direitos humanos.

\footnotetext{
16 "It is increasingly recognized that human rights are essential to achieve sustainable development. The Millennium Development Goals (MDGs) served as a proxy for certain economic and social rights but ignored other important human rights linkages. By contrast, human rights principles and standards are now strongly reflected in an ambitious new global development framework, the $\underline{2030}$ Agenda for Sustainable Development. [...]The SDGs are the result of the most consultative and inclusive process in the history of the United Nations. Grounded in international human rights law, the agenda offers critical opportunities to further advance the realization of human rights for all people everywhere, without discrimination."

${ }_{17}$ Os ODS são: 1. Erradicar a pobreza; 2. Erradicar a fome; 3. Saúde de qualidade; 4 . Educação de qualidade; 5 . Igualdade de gênero; 6 . Água potável e saneamento; 7. Energias renováveis e acessíveis; 8. Trabalho digno e crescimento econômico; 9. Indústria, inovação e infraestrutura; 10. Reduzir as desigualdades; 11. Cidades e comunidades sustentáveis; 12. Produção e consumo sustentáveis; 13 . Ação climática; 14. Proteger a vida marinha; 15. Proteger a vida terrestre; 16. Paz, justiça e instituições eficazes; 17. Parcerias para a implementação dos objetivos.
} 
Todavia, os ODS deixam mais nítido a sobreposição entre direitos humanos e meio ambiente evidenciada a partir da ligação entre sustentabilidade e direitos humanos. Os direitos humanos são incluídos de forma mais ampla e são colocados como um conceito chave, ao implicar a garantia dos direitos básicos na significação de como se atingir esse tipo de desenvolvimento (HAWKINS, 2010).

Outro ponto relevante a ser mencionado, é o fato de os ODS reconhecerem de forma muito mais enfática do que as agendas anteriores a ligação entre o global e o local. Assim, a superação dos desafios contemporâneos e o alcance do desenvolvimento sustentável ${ }^{18}$ dependem da articulação entre diversos setores da sociedade, carecendo não apenas do compromisso e a prática dos Estados, mas também do envolvimento de stakeholders e da sociedade civil (UN, 2015). Desse modo, nota-se que os ODS mantêm a estratégia de se aproximar dos indivíduos, contudo superam os ODM ao realizarem uma "convocação global" para que sejam adotadas medidas com vistas a garantir o desenvolvimento sustentável.

Não obstante, o que percebemos é que a despeito dos avanços conquistados pela Agenda 2030 e pelos ODS, limitações ainda permanecem na tentativa das Nações Unidas de conectar as agendas ambiental e dos direitos humanos. Como aponta Conca (2016) os objetivos relacionados ao meio ambiente ${ }^{19}$ não foram muito eficientes em explicitar a codificação dos direitos humanos que os sustentam, como por exemplo ausência de alusões ao direito à informação, à participação e à justiça nos ODS, um avanço conquistado na Declaração do Rio (1992).

A despeito disso, observa-se na estratégia de implementação dos ODS que os resultados de seu cumprimento concretizam a proteção dos direitos fundamentais ao ter como meta final a garantia do bem-estar dos seres humanos. Portanto, mesmo nos ODS relacionados às questões ambientais que não evidenciam os direitos humanos em sua descrição, espera-se como resultado de sua efetivação a

\footnotetext{
${ }^{18}$ A concepção de desenvolvimento sustentável afirmada pelos ODS envolve a erradicação da pobreza em todas as suas formas e dimensões, o combate as desigualdades nos Estados e entre os Estados, a preservação do Planeta, a criação de um crescimento econômico sustentado, inclusivo e sustentável e o fomento da inclusão social (UN, 2015).

19 Dentre os ODS, aqueles que fazem alusão ao meio ambiente são: 2. Erradicar a fome; 6 . Água potável e saneamento; 7. Energias renováveis e acessíveis; 11. Cidades e comunidades sustentáveis; 12. Produção e consumo sustentáveis; 13. Ação climática; 14. Proteger a vida marinha; 15. Proteger a vida terrestre.
} 
garantia de um ambiente mais íntegro para a humanidade, que por sua vez qualificase como medida protetiva dos direitos humanos.

Independentemente dos avanços a serem conquistados pela última agenda proposta pela ONU, o que se buscou ressaltar nesta seção foram as diferentes estratégias elaboradas pelas Nações Unidas ao longo dos últimos 70 anos em sua trajetória de proteção dos direitos humanos. Ao englobar as preocupações ambientais ao ideários dos direitos humanos, a significação de um meio ambiente saudável para o usufruto integral dos direitos fundamentais foi uma consequência e, recentemente, se materializa a partir da concepção, disseminada pela organização, de desenvolvimento sustentável.

\section{Conclusão}

Tendo como objetivo apresentar a constituição das agendas de meio ambiente e de direitos humanos, assim como de analisar as estratégias adotadas pela ONU na significação do meio ambiente saudável como um direito humano, visualizou-se que quando constituídos, os principais marcos promotores dessas discussões conferiram avanços tanto de forma isolada, no seio de cada agenda, como na sobreposição das temáticas.

Como forma de enfrentar as adversidades ocasionadas pela desmedida ação antrópica no meio ambiente, a ONU contribuiu para o reconhecimento por parte da comunidade internacional da importância do meio ambiente para o usufruto dos direitos humanos e, como resultado, propôs espaços para que diversos atores pudessem debater ambas as temáticas, sobrepondo as agenda ao conceituar o meio ambiente saudável como um direito humano.

A nova pauta de discussão que emergiu no cenário internacional também contou com a atuação ativa da ONU como mais um agente a participar do processo político de proposição de medidas capazes de solucionar as questões enfrentadas pela humanidade atualmente. Diante disso, o conceito de desenvolvimento sustentável foi apropriado pela organização e disseminado como o caminho a partir do qual seria possível a conciliação entre o direito dos Estados ao desenvolvimento, 
e a preservação ambiental, refletidas nas agendas adotadas pelas Nações Unidas desde 1992.

Com isso, buscamos evidenciar o importante papel desempenhado pela ONU no processo de criar significados, pautar agendas, influenciar discursos e implementar normativas e políticas passíveis de serem internalizadas por outros agentes em diferentes níveis de atuação. Apesar das limitações das propostas adotadas e dos resultados práticos, conclui-se que desde o início da trajetória de interrelação entre as agendas de meio ambiente e de direitos humanos, os fóruns de discussão das Nações Unidas, bem como seus documentos foram bem-sucedidos em significar o meio ambiente saudável como um direito humano e ressaltar a relação intrínseca entre essas duas áreas.

\section{Referências}

BÉLAND, Daniel; COX, Robert H. Ideas and Politics in Social Science Research. Oxford: Oxford University Press, 2011.

BONAVIDES, Paulo. Curso de direito constitucional. São Paulo: Malheiros, 1993.

BOYLE, Alan. Human Rights or Environmental Rights? A Reassessment. Fordham Environmental Law Review, v. 18, n. 3, p. 471-511, 2007.

BOYLE, Kevin. Stock-taking on Human Rights: The World Conference on Human Rights, Vienna 1993. Political Studies Association, v. XLIII, p. 79-95, 1995.

BRAUN, Ricardo. Novos Paradigmas Ambientais: desenvolvimento ao ponto sustentável. Petrópolis, RJ: Vozes, 2005.

BRÜSEKE, Franz Josef. O problema do Desenvolvimento Sustentável.

In: CAVALCANTI, Clovis (org). Desenvolvimento e natureza: estudo para uma sociedade sustentável. São Paulo: Cortez; Recife, PE: Fundação Joaquim Nabuco, 1998.

BUERGENTHAL, Thomas. The evolving International Human Rights System. The American Journal of International Law, v. 100, n. 4, p. 783-807, 2006.

CANÇADO TRINDADE, Augusto. Tratado de direito internacional dos direitos humanos. Porto Alegre: Sergio Antonio Fabris Editor, 2003.

CARSON, Rachel. Silent Spring. New York: Houghton Mifflin, 1962. 
CHASEK, Pamela S.; DOWNIE, David L.; BROWN, Janet Welsh. Global Environmental Politics. Boulder: Westview Press, 2017.

CMIEL, Kenneth. The recent history of Human Rights. The American Historical Review, v. 109, n. 1, p. 117-135, 2004.

CONCA, Ken. Rights and Environmental Protection Following Paris and the SDGs. Toward a Stronger Role for the United Nations. New York: The Friedrich-EbertStiftung, 2016.

FEHLING, Maya; NELSON, Brett D.; VENKATAPURAM, Sridhar. Limitations of the Millennium Development Goals: a literature review. Global Public Health, v. 8, n. 10, p. 1109-1122, 2013.

FINNEMORE, Martha; SIKKINK, Kathryn. Taking Stock: The Constructivist Research Program in International Relations and Comparative Politics. Annual Review of Political Science, v. 4, p. 391-416, 2001.

FURTADO, Emmanuel T.; MENDES, Ana Stela V. Os Direitos Humanos de $5^{\circ}$ geração enquanto direito à paz e seus reflexos no mundo do trabalho - inércias, avanços e retrocessos na Constituição Federal e na legislação. Anais do XVII Congresso Nacional do CONPEDI. Brasília, 2008.

HARDING, Ronnie. Ecologically sustainable development: origins, implementation and challenges. Desalination, v. 187, p. 229-239, 2006.

HAWKINS, Catherine A. Sustainability, human rights, and environmental justice: Critical connections for contemporary social work. Critical Social Work, v. 11, n. 3, 2010.

HERNANDEZ, Matheus. O Alto Comissário das Nacões Unidas para os Direitos Humanos e seu escritório: criação e desenvolvimento institucional (1994-2014). $483 f$. Tese (Doutorado em Ciência Política), Universidade Estadual de Campinas, Campinas, 2015.

HEYNS; Christof; PADILLA, David; ZWAAK, Leo. Comparação esquemática dos Sistemas Regional de Direitos Humanos: uma atualização. SUR - Revista Internacional de Direitos Humanos, n. 4, p. 161-169, 2006.

HORN, Laura. Rio+20 United Nations Conference on Sustainable Development: is this the future we want? MqJICEL, v. 9, n.1, p. 1-27, 2013.

JUTTA, Joachim M. Agenda Setting, the UN, and NGOs. Gender Violence and Reproductive Rights. Washington: Georgewown University Press, 2007.

KNOX, John H. Human Rights, Environmental protection, and the Sustainable Development Goals. Washington International Law Journal Association, v. 24, n. 3, p. 517-536, 2015. 
LEITE José Rubens Morato; AYALA, Patryck de Araújo. Direito ambiental na Sociedade de Risco. Rio de Janeiro: Forense Universitária, 2004.

LUÑO, Antonio Enrique Pérez. Derechos Humanos, Estado de Derecho y Constitución. Tecnos, 2005.

MARTIN, Lisa L.; SIMMONS, Beth A. Theories and Empirical Studies of International Institutions. International Organization, v. 52, n. 4, p. 729-757, 1998.

MAZZUOLLI, Valério de Oliveira. Curso de direito internacional público. São Paulo: Revistas dos Tribunais, 2013.

MINISTÉRIO DO MEIO AMBIENTE (MMA). Convenção-Quadro das Nações Unidas sobre Mudança do Clima (UNFCCC). Disponível em: < http://www.mma.gov.br/clima/convencao-das-nacoes-unidas >. Acessado em $01 \mathrm{de}$ outubro de 2018.

MOYN, Samuel. O futuro dos Direitos Humanos. Sur - Revista Internacional de Direitos Humanos, v. 1, n.1, p. 61-70, 2004.

NATIONAL RESEARCH COUNCIL OF THE NATIONAL ACADEMIES (NRCNA). Down to Earth: Geographic information for Sustainable Development in Africa. Washington: The National Academies Press, 2002.

OFFICE OF THE HIGH COMISSIONER FOR HUMAN RIGHTS (OHCHR). Human Rights and the 2030 Agenda for Sustainable Development. Disponível em: <http://www.ohchr.org/EN/lssues/MDG/Pages/The2030Agenda.aspx>. Acessado em 17 de novembro de 2017.

OLIVEIRA, Leandro Dias de. A geopolítica do desenvolvimento sustentável: um estudo sobre a Conferência do Rio de Janeiro (Rio-92). 267 f. Tese (Doutorado em Geografia). Universidade Estadual de Campinas, Campinas, 2015.

ORGANIZAÇÃO DAS NAÇÕES UNIDAS (ONU). Declaração Universal dos Direitos Humanos. $1948 . \quad$ Disponível em: http://www.ohchr.org/EN/UDHR/Documents/UDHR Translations/por.pdf>. Acessado em 18 de novembro de 2017.

PEARCE, David. et al. Blueprint for a green economy. London: Earthscan, 1989

PERREZ, Franz. Key questions concerning the human rights and environment debate: An introduction. In: United Nations Environment Programme for the Geneva Environment Network. Human Rights and the Environment. Proceedings of a Geneva Environment Network Roundtable, 2004.

PIOVESAN, Flavia. Direitos Sociais, Econômicos e Culturais e Direitos Civis e Políticos. Sur - Revista Internacional de Direitos Humanos, n. 1, p. 21-47, 2004.

Direitos Humanos: desafios na ordem internacional contemporânea. In 
PIOVESAN, Flávia (coord.). Direitos Humanos. vol.I, Curitiba: Juruá, 2006.

Editora Saraiva, 2010.

- Direitos Humanos e o Direito Constitucional Internacional. São Paulo:

PISANI, Jacobus. Sustainable development - historical roots of the concept. Environment Sciences, v. 3, n. 2, p. 83-96, 2006.

REDCLIFT, Michael. Sustainable development: exploring the contradictions. London: Routledge; New York: Methuen, 1987.

RICHARDSON, Dick. The politics of sustainable development. In: BAKER, Susan. et al. (Org.). The politics of sustainable development: theory, policy and practice within the european union. London: Makron Books, 1997.

ROCHESTER, J. Martin. The Rise and the Fall of International Organization as a Field of Study. International Organization, v. 40, n. 4, p. 77-813, 1986.

ROMITA, Arion Sayão. Direitos fundamentais nas relações de trabalho. São Paulo: LTr, 2007

UNITED NATIONS (UN). Report of the United Nations Conference on the Human Environment. Stockholm, 1972. Disponível em: < http://www.undocuments.net/aconf48-14r1.pdf>. Acessado em 10 de novembro de 2017.

Common Future: Report of the World Commission on Environment and Development. A/42/427, 1987. Disponível em: <http://www.un-documents.net/ocf02.htm\#l>. Acessado em 30 de setembro de 2018.

1994.

. Final Report prepared by Mrs. Fatma Zohra Ksentini, Special Rapporteur. https://digitallibrary.un.org/record/226681/files/E_CN.4_Sub.2_1994_9-EN.pdf>. Acessado em 10 de novembro de 2017.

Transforming our world: the 2030 agenda for sustainable development.

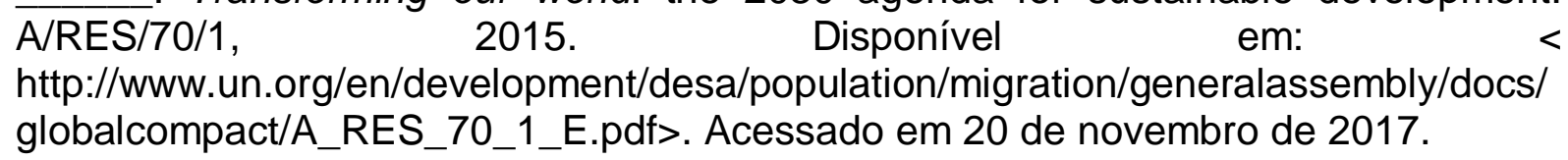

UNITED NATIONS ASSOCIATION IN CANADA (UNAC). The Human Rights approach to Sustainable Development. Environmental Rights, public participation and Human Security. 2013. Disponível em: http://unac.org/wpcontent/uploads/2013/07/HRandSD-EN-PDF.pdf. Acessado em 26 de novembro de 2017.

UNITED NATIONS GENERAL ASSEMBLY (UNGA). Problems of the Human Environment. UNGA Resolution 2398 (XXIII), 1968. Disponível em: < https://documents-dds- 
ny.un.org/doc/RESOLUTION/GEN/NR0/243/58/IMG/NR024358.pdf?OpenElement>. Acessado em 28 de novembro de 2017.

UNITED NATIONS CHILDREN'S FUND (UNICEF). Objetivos do Desenvolvimento do Milênio. Disponível em: < https://www.unicef.org/brazil/pt/resources 9540.htm>. Acessado em 02 de janeiro de 2018.

WACKERMANN, Gabriel. Le développment durable. Paris: Ellipses, 2008.

WEIS, Carlos. Direitos humanos contemporâneo. São Paulo: Malheiros, 2010.

Recebido em: 03/04/2018

Aprovado em: 03/11/2018 